\title{
Strategies To Achieve Control over the Surface Ratio of Two Different Components on Modified Electrodes Using Aryldiazonium Salts
}

\author{
Cheng Jiang, Muhammad Tanzirul Alam, Stephen G. Parker, Nadim Darwish, and J. Justin Gooding*
}

School of Chemistry, Australian Centre for NanoMedicine and ARC Centre of Excellence in Convergent Bio-Nano Science and Technology, The University of New South Wales, Sydney, NSW 2052, Australia

\section{Supporting Information}

ABSTRACT: Controlling the composition of an interface is very important in tuning the chemical and physical properties of a surface in many applications including biosensors, biomaterials, and chemical catalysis. Frequently, this requires one molecular component to a minor component in a mixed layer. Such subtle control of composition has been difficult to achieve using aryldiazonium salts. Herein, aryldiazonium salts of carboxyphenyl (CP) and phenylphosphorylcholine (PPC), generated in situ from their corresponding anilines, are electrografted to form molecular platform that are available for further functionalization. These two components are chosen because $\mathrm{CP}$ provides a convenient functionality for further coupling of biorecognition species while PPC offers resistance to nonspecific adsorption of proteins to the

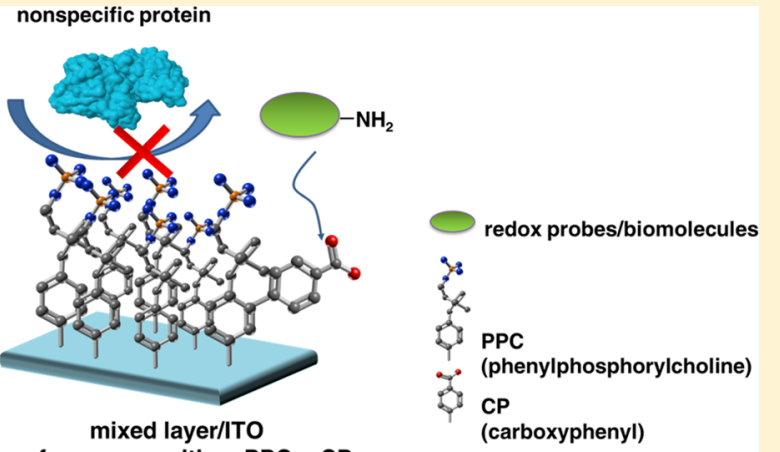

surface composition: $\mathrm{PPC}>>\mathrm{CP}$ surface. Mixed layers of CP and PPC were prepared by grafting them either simultaneously or consecutively. The latter strategy allows an interface to be developed in a controlled way where one component is at levels of less than $1 \%$ of the total layer.

\section{INTRODUCTION}

The benefits of introducing multiple functionalities through decorating a surface with organic layers have been well demonstrated in a large variety of applications, including surface wetting, ${ }^{1}$ cell biology, ${ }^{2,3}$ chemical sensing, ${ }^{4}$ biosensing, ${ }^{5,6}$ and photosynthesis. ${ }^{7}$ For example, alkanethiols have been used successfully in tailoring electrode surfaces with multiple functionalities in a controllable way in order to tune the chemical and physical properties of the surface. This has mainly been performed by exposing a gold substrate to a solution containing two alkanethiols with different functional groups. $^{8-10}$ The attractiveness of gold-thiol chemistry is the ease of forming well-organized monolayers with a controllable surface composition. ${ }^{11,12}$ Nonetheless, studies of alkanethiols on gold surfaces have revealed a few limitations with regards to the stability of the gold-thiolate bond and hence the stability of the resultant self-assembled monolayers (SAMs). It is reported that alkanethiols gradually desorb at temperatures over $100{ }^{\circ} \mathrm{C}$, leading to a mobile surface with the monolayer moving across the electrode surface. ${ }^{13,14}$ Furthermore, the surface-bound alkanethiol is prone to oxidation with resultant loss of the SAM from the surface. ${ }^{15}$ Such limitations compromises the viability of using gold-thiol-based SAMs for some applications where long-term use or high temperatures are required.

Thus, it would therefore be desirable to develop an approach that yields a stronger bond between an electrode surface and an organic layer while maintaining a controllable surface composition. Covalent modification of conducting or semiconducting surfaces via electrochemically reductive adsorption of aryldiazonium salts is a promising alternative that has attracted wide attention in recent times. ${ }^{16-18}$ In this regard, a mixed component from aryldiazonium salts with similar or different electrochemical reactivity can be formed on the electrode by depositing them to give multiple functionalities. ${ }^{4,19-22}$ Reductive attachment of mixtures of aryldiazonium salts leads to a modified surface with mixed organic layers, but the final structural composition is hard to control due to the high and unselective reactivity of the aryl radicals generated. ${ }^{14}$ Furthermore, it was found that the ratio of the two components on the surface is dominated by the reduction potentials of the two aryldiazonium salts as distinct from their ratio in solution; the more easily reduced (more positive reduction potential) diazonium salt gives greater surface coverage than expected from its concentration in solution. ${ }^{6,23,24}$ One exception to the above statement about poor control over layer composition due to different redox potentials of reductive adsorption has been demonstrated by the Gooding group where supramolecular interactions between the two aryldiazonium species bearing $-\mathrm{SO}_{3}{ }^{-}$or $-\mathrm{N}^{+}\left(\mathrm{CH}_{3}\right)_{3}$ in solution ensured that the ratio on the surface of the two components was always 1:1 even if different molar ratios were used. ${ }^{22}$ Of course, such a strategy does not allow low amounts of one component in a background of another to be formed. Gam-Derouich and co-workers have recently reported that formation of a mixed layer surface with

Received: December 14, 2015

Revised: February 17, 2016

Published: February 22, 2016 
Scheme 1. Electrografting Mixed Layer of PPC and CP on ITO Using (a) Simultaneous Electrografting Strategy and (b) Consecutive Electrografting Strategy ${ }^{a}$

a simultaneous electrografting

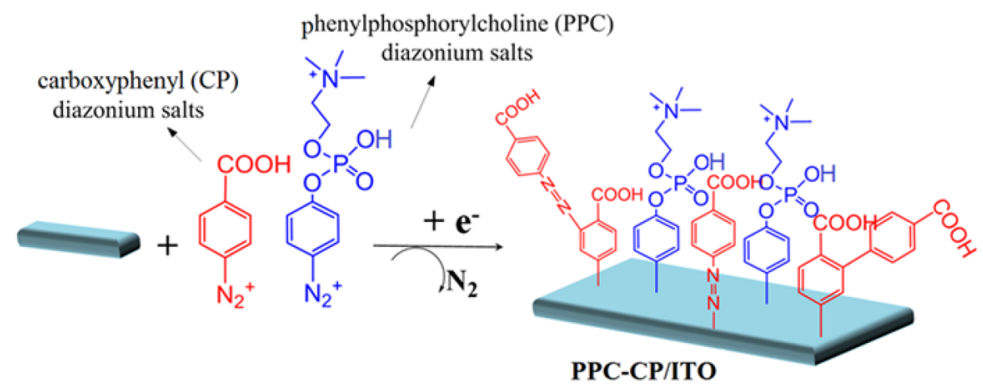

b consecutive electrografting
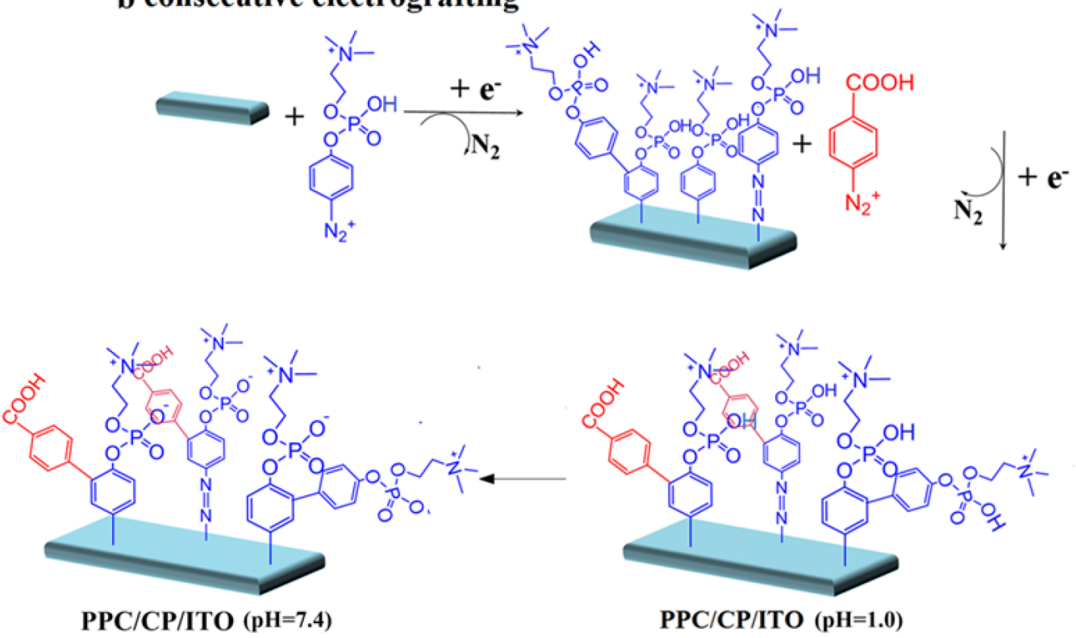

${ }^{a}$ In the former strategy, PPC and CP diazonium salts were deposited from mixtures of PPC and CP aryldiazonium salts at different molar ratios. In the latter strategy, PPC diazonium salt was selectively deposited first, followed by depositing CP diazonium salts on PPC modified surface. PPC-CP and $\mathrm{PPC} / \mathrm{CP}$ were used to distinguish and represent mixed layer deposited by simultaneous and consecutive strategies, respectively.

both antifouling and biorecognition properties through electrografting of 4-benzoylphenyl layer (BP) and surface-initiate photopolymerization of polyglycidol on BP. In that case the polyglycidol layer is a high-impedance layer, which blocks electron transfer, and the surface composition was not controlled in their study, and hence the work is less suited to electrochemical sensors. ${ }^{25}$

A sophisticated example of forming mixed layers using aryldiazonium salts is where a surface was modified with a mixture containing a molecular wire and a diluent that provided resistance to nonspecific adsorption of proteins to give electrodes for efficient electron transfer to redox proteins ${ }^{26}$ and for immunosensors. ${ }^{6,27}$ These electrodes were shown to be effective in a complex media. In the immunosensor study, an oligophenylethynylene molecular wire and an oligo(ethylene glycol)-terminated antifouling component were attached on a glassy carbon surface. ${ }^{6}$ The molecular wire enables electrochemical communication between the electrode and a redox species attached to its distal end, and the oligo(ethylene glycol) layers resists nonspecific adsorption of proteins to the surface. For immunosensor applications, the ideal interface was composed of a small amount of molecular wire in a background of dominating oligo(ethylene glycol). However, because the molecular wire was reductively adsorbed at a more positive redox potential than the oligo(ethylene glycol), even a 1:100 ratio of molecular wire to oligo(ethylene glycol) in solution resulted in only an approximate 1:3 ratio on the surface. This study illustrates that in a simultaneous electrodeposition strategy there is poor control over the surface composition when the two components do not have the same redox potentials.

Hence, a precise control over the surface composition is required to realize that one component is highly diluted while another component dominates the surface. This is especially crucial for making cell chips or electrochemical biosensors where the recognition component is diluted in an antifouling film so that interactions with target analytes are not sterically hindered and nonspecific protein adsorption is minimized. ${ }^{28-30}$

In this work, we are aiming to achieve control over the surface composition of aryldiazonium salt-derived mixed layers where one component is in excess of the other. Our interest is in developing an interface for biosensing applications, and very recently we have reported that aryldiazonium salts produced from zwitterionic 4-aminophenylphosphorylcholine can be electrodeposited on glassy carbon, ${ }^{31}$ gold $^{32}$ and indium tin oxide (ITO). ${ }^{33}$ The resulting modified electrodes are resistant to nonspecific protein adsorption, but the coating is of sufficiently low impedance that the electrode was still capable of supporting appreciable electron transfer across the layer. Hence, to render this idea compatible with biosensing 
interfaces requires an additional minor component in the interface for attaching biomolecules used as the recognition element in a biosensor. How to fabricate such interfaces is the purpose of this study. Specifically, a mixed layer surface containing a phenylphosphorylcholine (PPC) group and a carboxyl phenyl (CP) group formed on an ITO surface was investigated. A comparison was made between the control over the layer composition achieved using simultaneous and consecutive electrodeposition strategies (Scheme. 1).

\section{EXPERIMENTAL SECTION}

2.1. Reagents and Materials. Dichloromethane, methanol, $\mathrm{K}_{2} \mathrm{CO}_{3}, \mathrm{NaNO}_{2}, \mathrm{KCl}, \mathrm{NaCl}, \mathrm{HCl}(32 \%), \mathrm{KH}_{2} \mathrm{PO}_{4}$, and $\mathrm{Na}_{2} \mathrm{HPO}_{4}$ were purchased from Ajax Finecham (Sydney, Australia). 4-Aminophenylphosphorylcholine was obtained from Toronto Research Chemicals (Toronto, Canada). Human serum albumin (HSA), 1ethyl-3-(3-(dimethylamino)propyl)carbodiimide hydrochloride (EDC), and $\mathrm{N}$-hydroxysuccinimide (NHS) were acquired from Sigma (Sydney, Australia). ITO-coated glass slides (15-30 ohm/sq, $6480-\mathrm{AB}$ ) were obtained from SPI (West Chester, USA). All chemicals were used as received unless otherwise stated and aqueous solutions were prepared using Milli- $Q$ water $\left(18 \mathrm{M} \Omega \mathrm{cm}^{-1}\right.$, Millipore, Sydney, Australia). 1-Propylamino-1,2,3-triazole-4-ferrocene was synthesized using a "click" reaction with ethynylferrocene and 3-azido-1-propylamine as described by our group elsewhere. ${ }^{34}$ Phosphate-buffered saline (PBS) was used to dissolve HSA.

2.2. Modification of ITO Electrode Surfaces. ITO electrodes were sonicated successively with dichloromethane (DCM, $10 \mathrm{~min}$ ), methanol (10 $\mathrm{min}$ ), and $0.5 \mathrm{M} \mathrm{K}_{2} \mathrm{CO}_{3}$ in 2:1 (volume ratio) of methanol: $\mathrm{H}_{2} \mathrm{O}(30 \mathrm{~min})$, followed by rinsing with copious amounts of Milli-Q water and were dried under a stream of nitrogen. The electrodes were then modified either by cycling the potential between 0.2 and -0.65 at $0.1 \mathrm{~V} / \mathrm{s}$ in a $0.1 \mathrm{M} \mathrm{HCl}$ solution containing a diazonium salt mixture of PPC and CP (molar ratio 1:1) and equivalent amounts of $\mathrm{NaNO}_{2}$ or by a potentiostatic method through fixing the potential at $-0.6 \mathrm{~V}$ for different durations.

2.3. Electrochemical Apparatus. Cyclic voltammetry (CV) measurements were performed with an Autolab potentiostat (Metrohm Autolab B.V., Netherlands); ac voltammetry and electrochemical impedance spectroscopy (EIS) experiments were conducted using a Solartron SI 1287 electrochemical interface coupled with an SI 1260 frequency response analyzer (Solartron Analytical, Hampshire, England). All electrochemical experiments were carried out in a 2.0 $\mathrm{mL}$ one-compartment custom-made electrochemical cell comprising of a conventional three-electrode system, in which an O-ring was placed on the substrate to prevent solution leakage and to limit the contact area to a circle with surface area of $0.24 \mathrm{~cm}^{2}$. Electrochemical experiments were performed using ITO-coated glass as the working electrode, an $\mathrm{Ag} / \mathrm{AgCl}(3.0 \mathrm{M} \mathrm{KCl})$ as the reference electrode, and a platinum wire as the counter electrode.

2.4. Electrochemical Evaluation of Protein-Resistance Behavior. EIS to monitor the behavior of PPC-ITO in resisting nonspecific adsorption of proteins was performed in a redox probe solution of $0.1 \mathrm{M} \mathrm{KCl}$ containing $1 \mathrm{mM} \mathrm{K} \mathrm{K}_{3}\left[\mathrm{Fe}(\mathrm{CN})_{6}\right]$ and $1 \mathrm{mM}$ $\mathrm{K}_{4}\left[\mathrm{Fe}(\mathrm{CN})_{6}\right]$. The electrodeposited surfaces (PPC/ITO, CP/ITO, $\mathrm{PPC} / \mathrm{CP} / \mathrm{ITO}$ ) were rinsed thoroughly with water before adding them to the solution containing the redox probe, and EIS measurements were then performed. Subsequently, these electrodes were rinsed with water and PBS, followed by incubation in an HSA solution $(1 \mathrm{mg} / \mathrm{mL}$ HSA in PBS) for $1 \mathrm{~h}$. The electrodes were then rinsed thoroughly with PBS and Milli-Q water, followed by EIS measurement in a fresh redox probe solution. EIS spectra were recorded in the frequency range of $10^{5}-10^{-1} \mathrm{~Hz}$. An ac potential with $0.01 \mathrm{~V}$ peak-to-peak separation was superimposed on a dc potential of $0.212 \mathrm{~V}$. Impedance data was recorded and analyzed using ZPlot and ZView 3.1 software (Scribner Associates, Inc.), respectively.

2.5. X-ray Photoelectron Spectroscopy Characterization. XPS spectra were obtained using an EscaLab220-IXL spectrometer equipped with a monochromated $\mathrm{Al} \mathrm{K} \alpha$ source $(1486.6 \mathrm{eV})$, hemispherical analyzer, and multichannel detector. The spectra were accumulated at a takeoff angle of $90^{\circ}$ with a $0.79 \mathrm{~mm}^{2}$ spot size at a pressure of less than $1 \times 10^{-8} \mathrm{mbar}$. Binding energies of elements were corrected with reference to graphite $\mathrm{C} 1 \mathrm{~s}(284.6 \mathrm{eV})$. The XPS spectrum was analyzed with the Avantage software, involving background subtraction using the Shirley routine and a subsequent nonlinear least-squares fitting to mixed Gaussian-Lorentzian functions. The atomic concentration (atom. \%) of individual elements was determined from the relative peak area of the spectrum and the corresponding sensitivity factors according to eq 1 :

$$
\text { atom } \%=\frac{A_{i} / s_{i}}{\sum A_{i} / s_{i}}
$$

where $A_{i}$ is the area of the element $i$ and $s_{i}$ is the sensitivity factor for this element. The sensitivity factors for $\mathrm{P} 2 \mathrm{p}, \mathrm{O} 1 \mathrm{~s}, \mathrm{C} 1 \mathrm{~s}$, and $\mathrm{N} 1 \mathrm{~s}$ are $1.19,2.93,1.00$, and 1.80 , respectively. The thickness of the deposited layer on ITO is estimated from the relative attenuation of the In $3 \mathrm{~d}$ signal, using

$$
\ln \left(I / I_{0}\right)=(-d / \lambda) \sin (\theta)
$$

where $d$ is the layer thickness, $\lambda$ is the photoelectron escape depth of In $3 \mathrm{~d}$ which was estimated to be $3.5 \mathrm{~nm},{ }^{35} \theta$ is the takeoff angle $\left(90^{\circ}\right.$ used in our experiment), and $I / I_{0}$ is the ratio of the In $3 \mathrm{~d}$ peak intensities (modified surface/bare surface).

\section{RESULTS AND DISCUSSION}

Prior to examining the mixed layers formed by arydiazonium salts of CP and PPC, the reductive adsorption behavior of the two individual salts and the mixture of the two salts was investigated. A typical cyclic voltammogram of a $1 \mathrm{mM} \mathrm{CP}$ diazonium salt solution on the ITO surface shows a single irreversible reduction peak at $-0.26 \mathrm{~V}$ (Figure 1a) during the first reduction scan whereas PPC diazonium salts shows a reduction peak at $-0.54 \mathrm{~V}$ (Figure $1 \mathrm{~b}$ ). Importantly, the cyclic voltammogram of a mixed $\mathrm{PPC}-\mathrm{CP}$ diazonium salts solution (Figure 1c) exhibits two reduction peaks (appeared at potentials comparable to those in Figure 1a,b) in the first cycle, while in the following scans only the redox wave corresponding to $\mathrm{CP}$ diazonium salts was observed.

3.1. PPC-CP/ITO from Simultaneous Electrografting Strategy. A mixed layer surface of PPC-CP/ITO was first obtained by two voltammetric cycles in a solution of PPC-CP aryldiazonium salt mixture with a 1:1 molar ratio. The resultant surface was characterized by XPS and shown in Figure 2. The characteristic peaks for phosphorus (135 and $132.8 \mathrm{eV}$ ) and quaternary nitrogen $\left(-\mathrm{N}^{+}\left(\mathrm{CH}_{3}\right)_{3}\right)$ peak $(403 \mathrm{eV})$ from the $\mathrm{P}$ $2 \mathrm{p}$ and $\mathrm{N} 1 \mathrm{~s}$ narrow scans, respectively, allow the identification of PPC on the surface while the $289 \mathrm{eV}$ in the $\mathrm{C} 1$ s narrow is indicative of the $-\mathrm{COOH}$ of $\mathrm{CP}$. The surface ratio of $\mathrm{P} / \mathrm{N}$ (using atom \% (P)/atom \% $\left(-\mathrm{N}^{+}\left(\mathrm{CH}_{3}\right)_{3}\right)$ was found to be around $1: 1$, which is in good agreement with theoretical value of phosphorylcholine moiety of PPC. Thus, $\mathrm{COOH}$ and $\mathrm{P}$ were selected as XPS markers for CP and PPC, respectively. The surface ratio of PPC:CP was found to be 1:20 by using atom \% $(\mathrm{P}) /$ atom \% (COOH) (eq 1), which was not only significantly different from the 1:1 molar ratio in the deposition solution but also a long way from the desired outcome of a low amount of $\mathrm{CP}$ in a layer dominated by PPC.

To further study the relationship between molar ratio in solution and the corresponding surface ratio, a depositing potential of $-0.6 \mathrm{~V}$ (at which both PPC and CP diazonium salts can be reduced at same time) was chosen, in which the molar concentration of PPC was fixed at $1 \mathrm{mM}$ while the CP concentration in the deposition solution was varied. For 


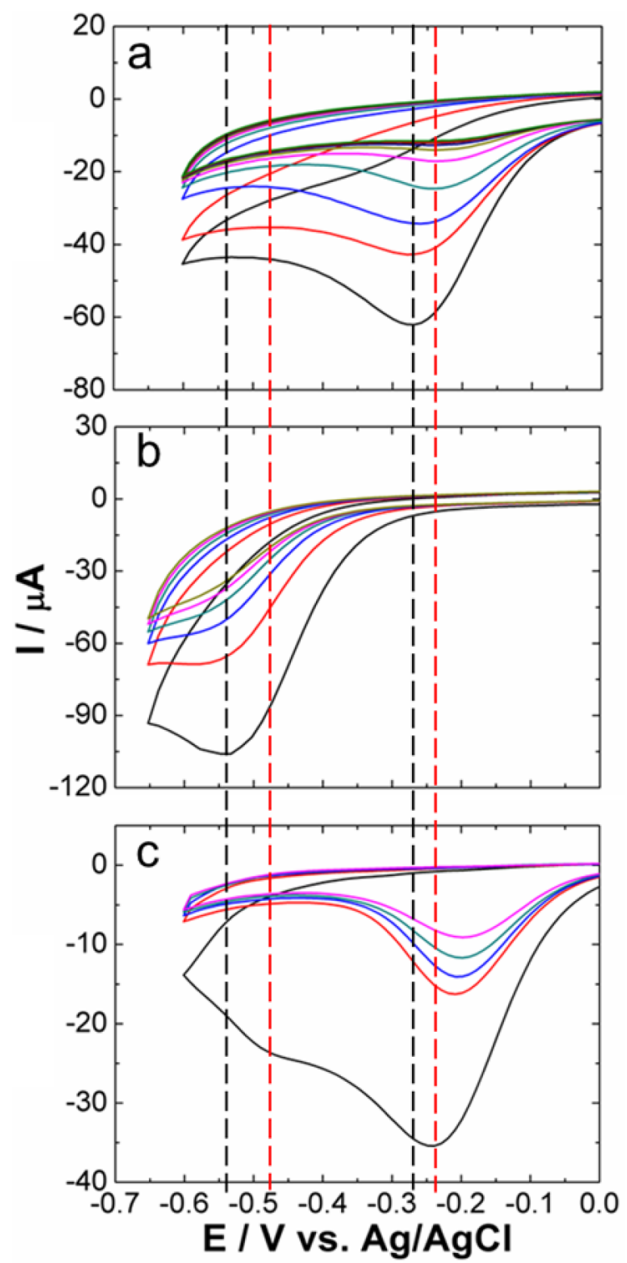

Figure 1. Cyclic voltammograms for reductive adsorption of aryldiazonium salts on an ITO electrode from (a) $1 \mathrm{mM}$ 4aminobenzoic acid (CP) in $0.1 \mathrm{M} \mathrm{HCl}$, (b) $1 \mathrm{mM}$ 4-aminophenylphosphorylcholine (PPC) in $0.1 \mathrm{M} \mathrm{HCl}$, and (c) $1 \mathrm{mM}$ mixture of 4aminobenzoic acid (CP) and 4-aminophenylphosphorylcholine (PPC) with 1:1 molar ratio in $0.1 \mathrm{M} \mathrm{HCl}$, with $1 \mathrm{mM} \mathrm{NaNO}_{2}$ at a scan rate of $0.1 \mathrm{~V} / \mathrm{s}$. The black dashed line indicates the reduction peak of the individual aryldiazonium salt, and the red dashed line indicates the reduction peaks of aryldiazonium salts mixture.

example, to obtain a mixture solution with $1: 5$ or $10000: 1$ molar ratio (PPC:CP), the concentration of $\mathrm{CP}$ was adjusted to $5 \mathrm{mM}$ or $0.1 \mu \mathrm{M}$ while keeping the concentration of PPC at 1 $\mathrm{mM}$. As shown in Figure 3, the increase in surface ratio of $\mathrm{PPC} / \mathrm{CP}$ lagged far behind the molar ratios in solution, for

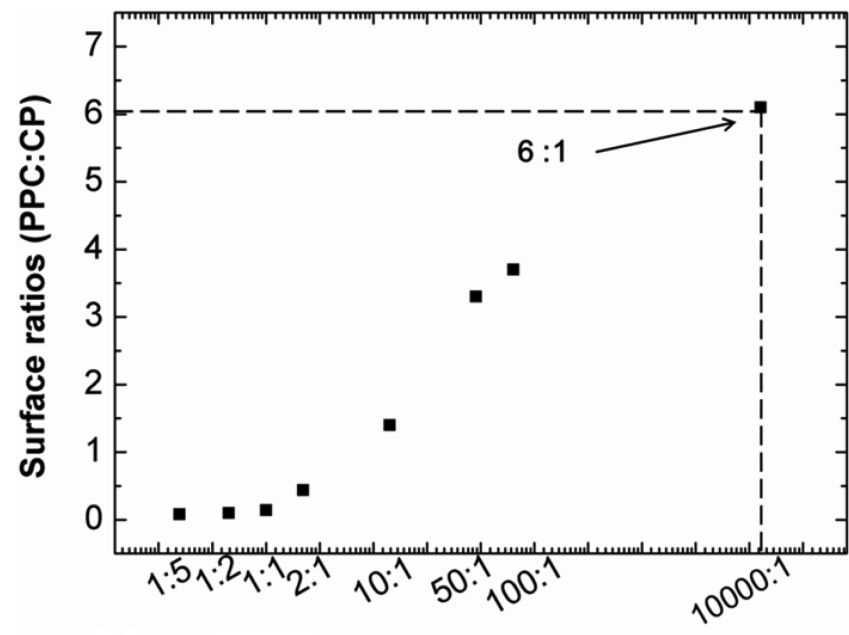

Molar ratios in deposition solution (PPC:CP)

Figure 3. Comparison of molar ratio of PPC-CP $(X)$ in mixed deposition solution to the XPS atomic ratio $(Y)$ of the $\mathrm{P} 2 \mathrm{p}$ narrow scan derived from PPC and the carboxyl peak in the $\mathrm{C}$ 1s narrow scan from $\mathrm{CP}$ in the PPC-CP/ITO mixed layer surfaces modified by the simultaneous electrografting approach. The deposition potential and deposition time were fixed at $-0.6 \mathrm{~V}$ and $5 \mathrm{~min}$, respectively.

example, when the molar ratio of PPC:CP was 1:5, 10:1, and 100:1, the surface ratio was found to be $1: 13.8,1.4: 1$, and $3.7: 1$, respectively. Even with 10000 times greater amounts of PPC over $\mathrm{CP}$, the surface ratio of PPC:CP increased to only $6: 1$. This can be explained by the more positive reduction potential of the CP diazonium which makes it easier to be reduced on the surface as compared to the PPC diazonium cations. It is believed that the grafting of the radicals is in competition with their reduction, ${ }^{36,37}$ leading to initially grafted CP species possibly inhibiting the adsorption of PPC to the surface. ${ }^{25}$ Such an assertion is also supported by the absence of a peak for PPC diazonium salts after the first cycle in the cyclic voltammogram of the diazonium salt mixture of PPC and CP shown in Figure 1c. A similar finding has been reported by Bélanger and coworkers $^{24}$ by depositing a binary mixture of 4-nitrophenyldiazonium cations (reduction potential $0.2 \mathrm{~V}$ ) and 4-bromophenyldiazonium cations (reduction potential $-0.2 \mathrm{~V}$ ) on glassy carbon. In the cyclic voltammogram recorded in such a mixture, only the reduction peak of nitrophenyldiazonium cations was observed. They also found that the grafted layer was always richer in nitrophenyl groups than in bromophenyl groups in comparison to the corresponding concentration of
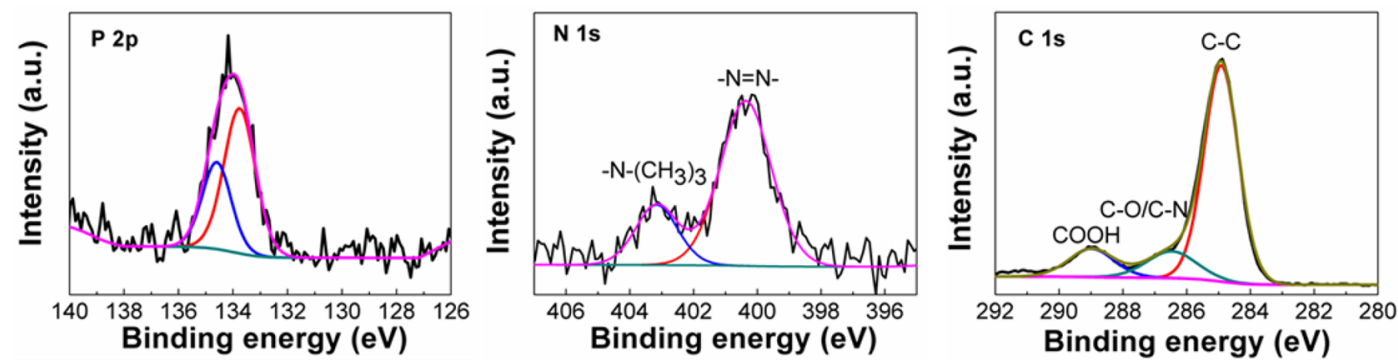

Figure 2. P 2p, N 1s, and C 1s core level XPS spectra for PPC-CP mixed layer modified-ITO after two voltammetric cycles (simultaneous electrografting approach). Electrografting is carried out in a solution of $0.1 \mathrm{M} \mathrm{HCl}$ containing PPC-CP diazonium salts with molar ratio of 1:1 and equivalent amount of $\mathrm{NaNO}_{2}$ in the potential range from 0.2 to $-0.65 \mathrm{~V}$ (vs $\mathrm{Ag} / \mathrm{AgCl}(3 \mathrm{M} \mathrm{KCl})$ ) using a scan rate of $0.1 \mathrm{~V} / \mathrm{s}$. 
the diazonium cations in the deposition mixture when applying an over potential of $-0.7 \mathrm{~V}$.

Interestingly, in the simultaneous electrografted PPC-CP mixed layer/ITO surface, the azo group intensity (located at $\sim 400 \mathrm{eV}$ ) seems to be positively correlated with the molar fraction of $\mathrm{CP}$ in the deposition solution but negatively correlated with that of PPC (Figure 4 and Figure S2). For
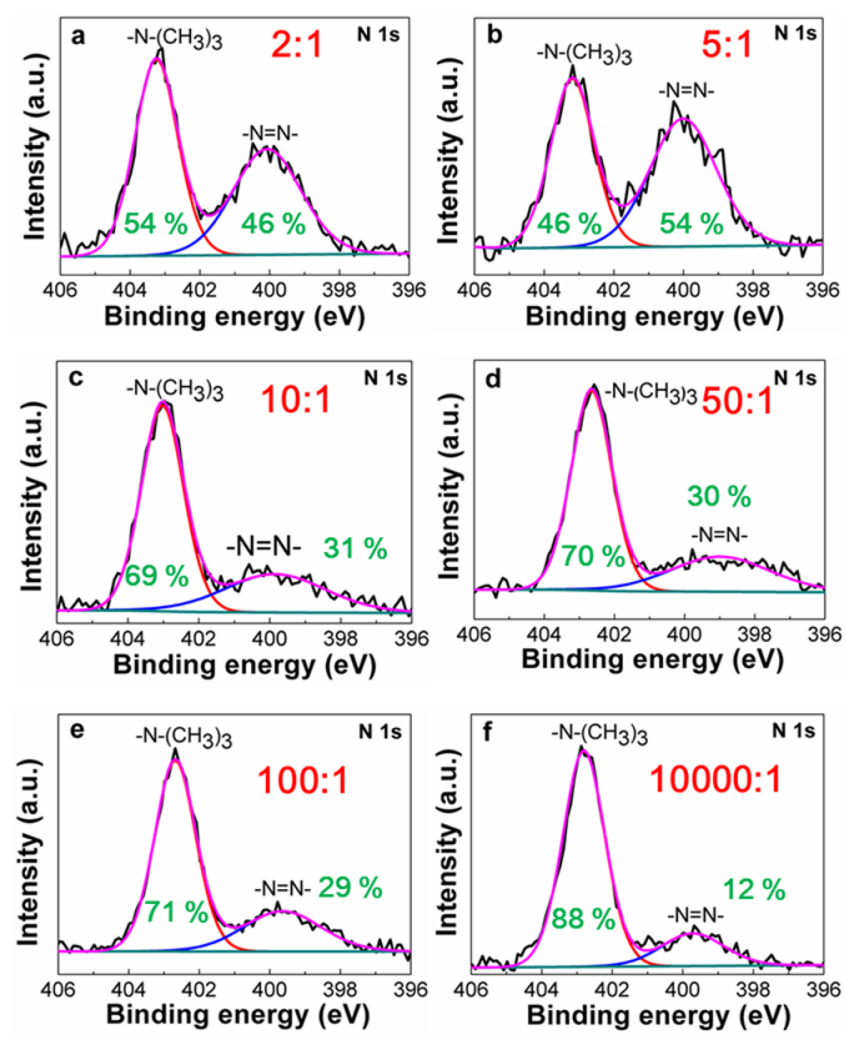

Figure 4. N 1s core level spectra of PPC-CP/ITO surfaces modified by the simultaneous electrografting approach from mixed deposition solution with different molar ratios (PPC takes more molar fraction than that of CP): (a) 2:1, (b) 5:1, (c) 10:1, (d) 50:1, (e) 100:1, and (f) 10000:1. Deposition potential and deposition time were fixed at $-0.6 \mathrm{~V}$ and $5 \mathrm{~min}$, respectively. The ratio in red represents the relative molar ratios in the deposition solution, and the percentage in green indicates the proportion of azo group $(-\mathrm{N}=\mathrm{N}-)$ and quaternary nitrogen $\left(-\mathrm{N}^{+}\left(\mathrm{CH}_{3}\right)_{3}\right)$ of the total nitrogen percentage on each surface.

example, when the molar ratio of $\mathrm{PPC}-\mathrm{CP}$ is $1: 5$, the azo group dominates the total $\mathrm{N}$, being $78 \%$ as shown in Figure S2c, while when the molar ratio of PPC-CP is 10000:1 (Figure $4 \mathrm{f})$, the quaternary nitrogen $\left(-\mathrm{N}^{+}\left(\mathrm{CH}_{3}\right)_{3}\right)$ peak dominates the total $\mathrm{N}$ at $88 \%$. These results indicate that $\mathrm{CP}$ diazonium cations can not only graft directly onto the ITO surface but also graft onto already deposited molecules to form multilayers. ${ }^{38,39}$ The results from the deposition of the individual aryl diazonium salts also showed that $\mathrm{CP}$ diazonium salt tends more likely to form the azo group in the layer than PPC diazonium salt (Figure S1).

3.2. $\mathrm{PPC} / \mathrm{CP} / \mathrm{ITO}$ from Consecutive Electrografting Strategy. As shown above, in the simultaneous electrografting strategy, the relative reactivity of the two aryldiazonium salts plays a key role in the surface composition. Thus, when a mixture of aryldiazonium species are present in solution, the one with higher reactivity dominates the surface composition irrespective of what molar fraction it represents in the solution. To achieve better control over the ratio of the two components on the surface such that one can enable the poorly reactive diazonium species to dominate on the ITO surface, a consecutive electrografting strategy was used. In this strategy, the PPC diazonium cations were selectively deposited first at $-0.6 \mathrm{~V}$ with higher concentrations and longer deposition times, followed by the electrodeposition of CP diazonium salts with a depositing potential at $-0.1 \mathrm{~V}$, lower concentrations, and shorter deposition times. It was found that a condition that deposited $1 \mathrm{mM}$ PPC diazonium salts at $-0.6 \mathrm{~V}$ for $5 \mathrm{~min}$, followed by depositing CP from highly diluted $(1 \mathrm{nM})$ solution at $-0.1 \mathrm{~V}$ for $5 \mathrm{~s}$, gave surfaces with a ratio of $200: 1 \mathrm{PPC} / \mathrm{CP}$ (shown in Table. 1).

Table 1. XPS Characterization of PPC/CP/ITO Surface Composition Derived from the Consecutive Electrografting Approach

\begin{tabular}{cc} 
electrodeposition conditions & $\begin{array}{c}\text { PPC/CP surface } \\
\text { ratio }\end{array}$ \\
$1 \mathrm{mM} \mathrm{PPC}-0.6 \mathrm{~V}, 30 \mathrm{~s}$, then $1 \mathrm{mM} \mathrm{CP}-0.6 \mathrm{~V}, 5 \mathrm{~s}$ & $2: 1$ \\
$1 \mathrm{mM} \mathrm{PPC}-0.6 \mathrm{~V}, 5 \mathrm{~min}$, then $1 \mu \mathrm{M} \mathrm{CP}-0.1 \mathrm{~V}, 5 \mathrm{~s}$ & $81: 1$ \\
$1 \mathrm{mM}$ PPC $-0.6 \mathrm{~V}, 5 \mathrm{~min}$, then $1 \mathrm{nM} \mathrm{CP}-0.1 \mathrm{~V}, 5 \mathrm{~s}$ & $200: 1$ \\
\hline
\end{tabular}

The CP layer was believed to grow mainly on the PPC layer due to the steric hindrance of the PC moiety and the multilayer structure of PPC ( $2.5 \mathrm{~nm}$ thickness, assumed to be about three layers considering length of PPC is around $0.8 \mathrm{~nm}$ ). Evidence from cyclic voltammograms showed that the reduction peak of $\mathrm{CP}$ on bare ITO is $-0.26 \mathrm{~V}$, while for $\mathrm{CP}$ on PPC/ITO (consecutive electrografting) the peak moved more positively to $-0.2 \mathrm{~V}$, indicating that $\mathrm{CP}$ was mostly growing on the PPC layer.

3.3. Evaluation of Protein-Resistant Behavior. Even though this method of forming mixed layers from aryldiazonium salts should be reasonably general, the purpose of forming mixed layers specifically from PPC and CP was to develop biosensing interfaces. In such interfaces, PPC would provide resistance to nonspecific adsorption of proteins while the $\mathrm{CP}$ would allow biorecognition molecules to be attached. In our previous study, $20 \mathrm{CV}$ scans on ITO were required to form PPC layers with good antifouling ability. ${ }^{33}$ Considering there is a risk that the deposition of CP on PPC may shield the PC moiety and affect the surface antifouling behavior, the deposited amount of CP in the consecutive electrografting approach was adjusted to retain the antifouling behavior and accessibility of the carboxylic acid group of the mixed layer/ ITO surface. This was examined by incubating the modified surfaces in a HSA solution and further decoration of ferrocene, respectively.

The antifouling behavior of the resultant mixed layer/ITO surfaces was studied using electrochemical impedance spectroscopy, in which bare ITO, PPC/ITO, and CP/ITO surfaces were used as controls. For functionalized surfaces of PPC/ITO (before HSA incubation, $493 \pm 4.7 \Omega \mathrm{cm}^{2}$ and after HSA incubation, $503 \pm 10 \Omega \mathrm{cm}^{2}$, Figure 5c) and PPC/CP/ITO (before HSA incubation, $542 \pm 22.5 \Omega \mathrm{cm}^{2}$, and after HSA, 520 $\pm 5 \Omega \mathrm{cm}^{2}$, Figure $5 \mathrm{~d}$ ) both showed good antifouling properties since the charge transfer resistance $\left(R_{\mathrm{ct}}\right)$ was similar before and after HSA incubation, indicating nonspecific proteins can be repulsed from the surface due to a hydrated layer formed by the interaction between the zwitterionic PPC 

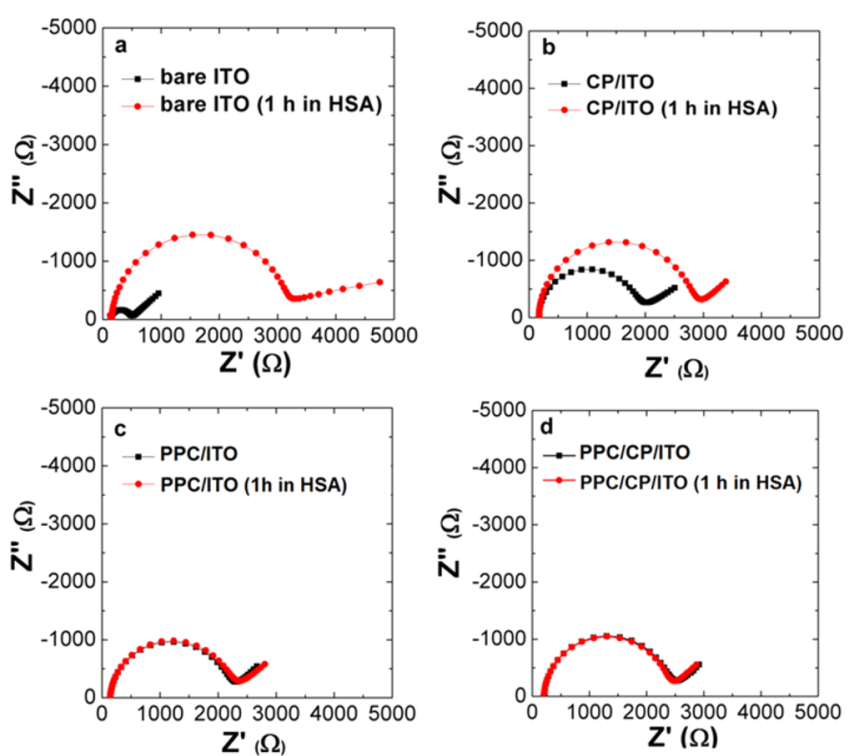

Figure 5. Nyquist plots comparing Faradaic impedance at surfaces of (a) bare ITO, (b) CP/ITO, (c) PPC/ITO, and (d) PPC/CP/ITO (with surface ratio 200:1 modified by consecutive electrografting approach) in a solution of $0.1 \mathrm{M} \mathrm{KCl}$ containing $1 \mathrm{mM} \mathrm{K}_{3}\left[\mathrm{Fe}(\mathrm{CN})_{6}\right]$ and $1 \mathrm{mM} \mathrm{K}_{4}\left[\mathrm{Fe}(\mathrm{CN})_{6}\right]$ before and after $1 \mathrm{~h}$ incubation in a protein solution ( $1 \mathrm{mg} / \mathrm{mL}$ HSA in PBS, $\mathrm{pH} 7.4)$.

moieties and water molecules. ${ }^{40,41}$ While for bare ITO (Figure $5 \mathrm{a}$ ) and CP/ITO (Figure 5b), the $R_{\mathrm{ct}}$ value increased significantly (for bare ITO, $R_{\mathrm{ct}}$ increased by almost 8 times after HSA incubation from $77 \pm 1.6 \Omega \mathrm{cm}^{2}$ to $686 \pm 11 \Omega \mathrm{cm}^{2}$, and for CP/ITO, $R_{\mathrm{ct}}$ increased by $50 \%$ from $414 \pm 3.5 \Omega \mathrm{cm}^{2}$ to $605 \pm 13.7 \Omega \mathrm{cm}^{2}$ ), indicating adsorption of HSA on such surfaces. It is worth noting that CP itself does not function as an antifouling layer; however, when it was grafted as a small percentage of the layer with PPC, it did not deleteriously affect the antifouling property of the surface as demonstrated by the almost nonvariance of charge transfer resistance in both the cases (Figure 5d).

One final concern regarding this method of forming mixed layers was whether the subsequent grafting would increase the charge transfer resistance across these layers by redox species in solution. This is important as the entire purpose was to develop PPC as a low-impedance antifouling layer such that electron transfer could still efficiently proceed. ${ }^{31}$ Figure S3 showed the blocking effect of such PPC/CP/ITO mixed layer surface from consecutive electrografting strategy with two clear redox peaks still clearly existing, implying that the mixed layer surface does not completely block electron transfer.

3.4. Functionalization of a Mixed Layer Surface with Ferrocene. To demonstrate that the carboxyl group in CP is free for further modification, ferrocene was attached to the surfaces of PPC/CP/ITO (200:1 surface ratio from consecutive electrografting), PPC-CP/ITO (surface ratio 6:1 from the simultaneous electrografting approach), and CP/ITO (control) with the aid of the EDC/NHS coupling reaction (Scheme 2). The electron transfer kinetics of the different surfaces was then

Scheme 2. Chemical Functionalization of (a) PPC-CP/ITO (with Surface Ratio 6:1 Modified by Simultaneous Electrografting approach), (b) PPC/CP/ITO (with Surface Ratio 200:1 Modified by Consecutive Electrografting Electrografting Approach), and (c) CP/ITO with 1-Propylamino-1,2,3-triazole-4-ferrocene

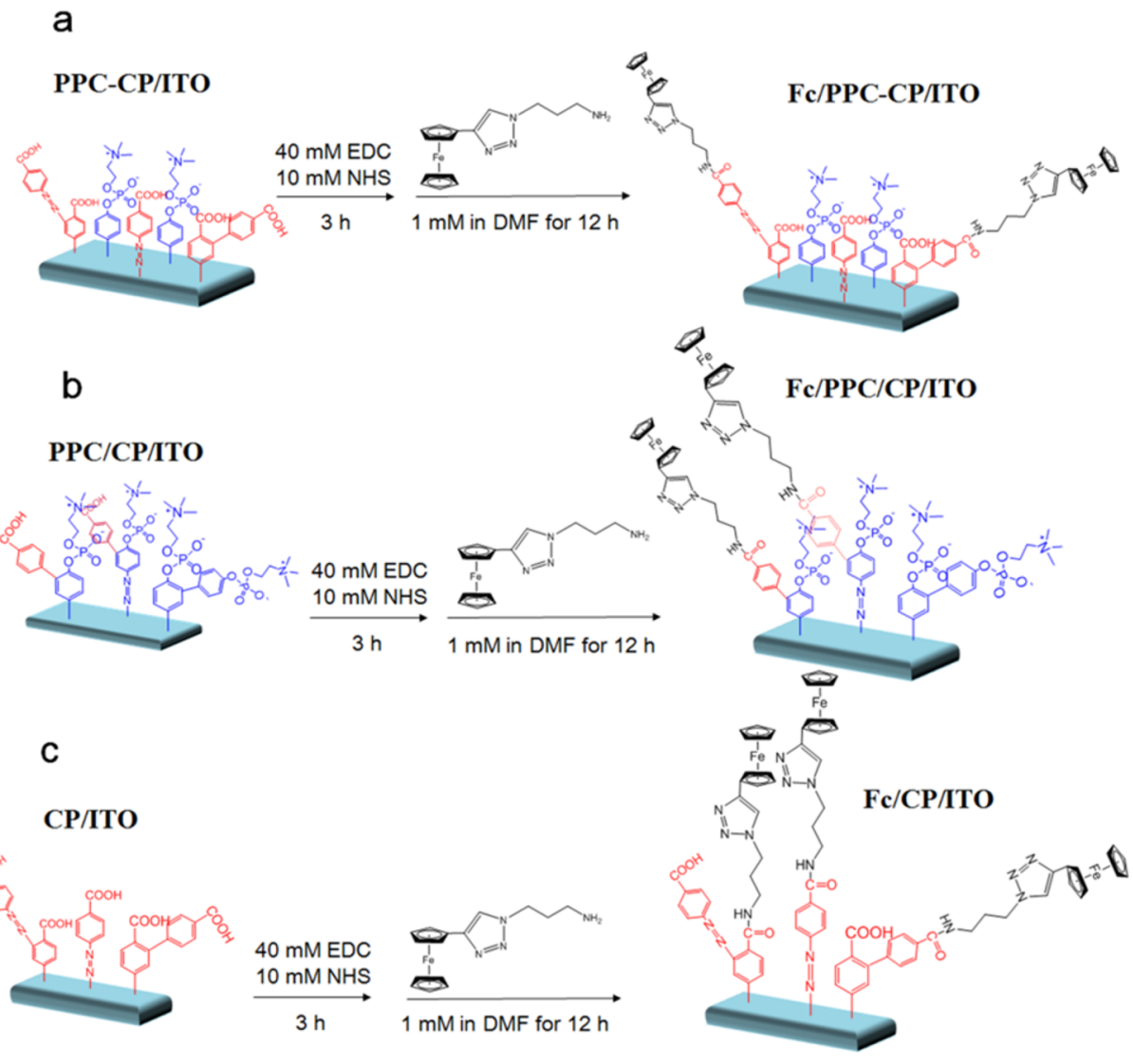



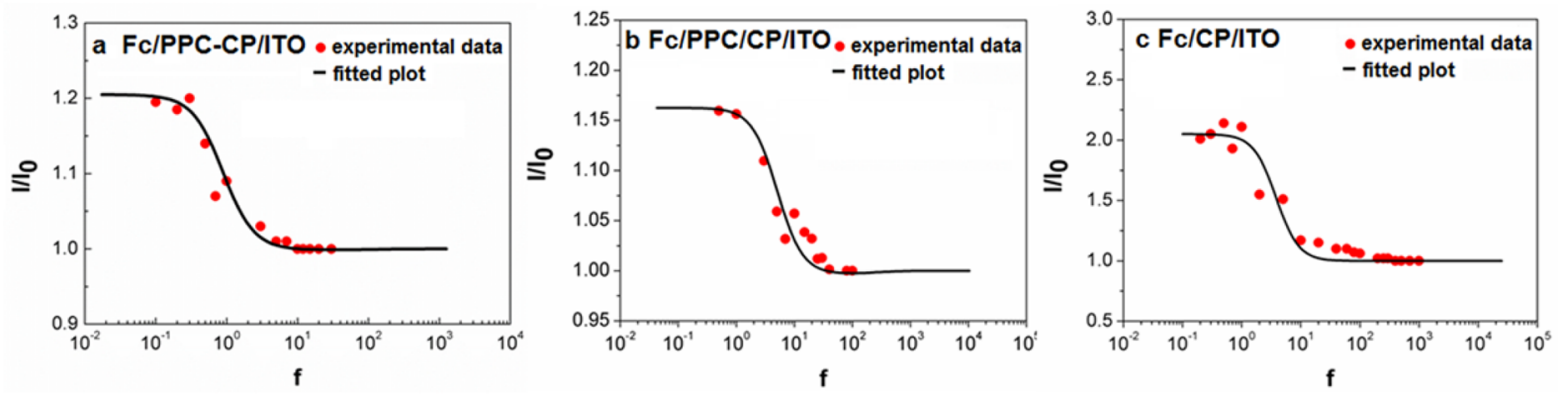

Figure 6. Plots of $I$ (peak)/I(background) vs $\log$ (frequency) prepared using ac voltammetry for (a) Fc/PPC-CP/ITO, (b) Fc/PPC/CP/ITO, and (c) $\mathrm{Fc} / \mathrm{CP} / \mathrm{ITO}$. Solid line shows fitted plot using equivalent circuit parameters $C_{\mathrm{dl}}=1.7 \times 10^{-6} \mathrm{~F}, R_{\mathrm{ct}}=1.1 \times 10^{5} \Omega, C_{\mathrm{ad}}=8.3 \times 10^{-6} \mathrm{~F}\left(k_{\mathrm{et}}=2.7\right.$ $\left.\mathrm{s}^{-1}\right) ; C_{\mathrm{dl}}=5.72 \times 10^{-6} \mathrm{~F}, R_{\mathrm{ct}}=8326 \Omega, C_{\mathrm{ad}}=4.75 \times 10^{-6} \mathrm{~F}\left(k_{\mathrm{et}}=12.6 \mathrm{~s}^{-1}\right)$; and $C_{\mathrm{dl}}=1.3 \times 10^{-6} \mathrm{~F}, R_{\mathrm{ct}}=2.5 \times 10^{5} \Omega$, and $C_{\mathrm{ad}}=8 \times 10^{-6} \mathrm{~F}\left(k_{\mathrm{et}}=\right.$ $15.4 \mathrm{~s}^{-1}$ ) for three surfaces $(\mathrm{a}-\mathrm{c})$, respectively.

examined using cyclic voltammetry and ac voltammetry (Creager method). ${ }^{42}$ From the CVs, the coverage of the ferrocene can be estimated to be $3.21 \times 10^{-11}, 2.17 \times 10^{-11}$, and $0.92 \times 10^{-11} \mathrm{~mol} \mathrm{~cm}^{-2}$ for the $\mathrm{Fc} / \mathrm{CP} / \mathrm{ITO}, \mathrm{Fc} / \mathrm{PPC} / \mathrm{CP} /$ ITO, and Fc/PPC-CP/ITO, respectively.

Ideally, the peak separation in CVs should be negligible for a well-defined redox system with the ferrocene and ferrocenium couple. In this case, the significant peak separation was noticeable for all surfaces, suggesting the electron transfer kinetics are slow on the time scale of the $0.1 \mathrm{~V} \mathrm{~s}^{-1}$ voltammetric scan. Smaller peak separation was found in $\mathrm{Fc}-\mathrm{CP} / \mathrm{ITO}$ compared to $\mathrm{Fc} / \mathrm{PPC}-\mathrm{CP} / \mathrm{ITO}$ and $\mathrm{Fc} / \mathrm{PPC} / \mathrm{CP} / \mathrm{ITO}$, implying electron transfer kinetics on both mixed layer/ITO surfaces is much slower than that of CP/ITO surface (Figure S4). The calculated $k_{\text {et }}$ values using ac voltammetry are in line with expectation. The value of $k_{\text {et }}$ was determined to be $15.4 \pm$ $2.2,12.6 \pm 1.7$, and $2.7 \pm 0.2 \mathrm{~s}^{-1}$ for $\mathrm{Fc} / \mathrm{CP} / \mathrm{ITO}, \mathrm{Fc} / \mathrm{PPC} /$ $\mathrm{CP} / \mathrm{ITO}$, and Fc/PPC-CP/ITO, respectively (Figure 6). The $k_{\text {et }}$ values calculated from the Laviron method were consistent with that from the Creager method $(16.9 \pm 0.3,17.2 \pm 2.5$, and $1.1 \pm 0.14 \mathrm{~s}^{-1}$ for three corresponding surfaces mentioned above) (Figure S4). It is expected that $k_{\text {et }}$ is independent from the surface coverage of ferrocene but is dependent on the distance between the ferrocene and the electrode surfaces. ${ }^{43,44}$ For $\mathrm{Fc} / \mathrm{CP} / \mathrm{ITO}$ and $\mathrm{Fc} / \mathrm{PPC} / \mathrm{CP} / \mathrm{ITO}$ surfaces the $k_{\mathrm{et}}$ value is comparable to and bigger than that of $\mathrm{Fc} / \mathrm{PPC}-\mathrm{CP} / \mathrm{ITO}$, indicating the distance of ferrocene to the electrode surface is in the order of $\mathrm{Fc} / \mathrm{CP} / \mathrm{ITO}<\mathrm{Fc} / \mathrm{PPC} / \mathrm{CP} / \mathrm{ITO}<\mathrm{Fc} / \mathrm{PPC}-\mathrm{CP} /$ ITO.

It is clear that the electron transfer behavior is different between the mixed surface fabricated from simultaneous electrografting $(\mathrm{Fc} / \mathrm{PPC}-\mathrm{CP} / \mathrm{ITO})$ and consecutive electrografting $(\mathrm{Fc} / \mathrm{PPC} / \mathrm{CP} / \mathrm{ITO})$ procedures. It is exciting that $\mathrm{CP}$ groups on PPC can still allow sufficient electron transfer in the $\mathrm{Fc} / \mathrm{PPC} / \mathrm{CP} / \mathrm{ITO}$ surface, while for $\mathrm{Fc} / \mathrm{PPC}-\mathrm{CP} / \mathrm{ITO}$, electron transfer is quite slow. Through the rough estimation of film thickness of the three surfaces using eq 2 , it is in the order of PPC-CP/ITO $(2.9 \mathrm{~nm})<\mathrm{CP} / \mathrm{ITO}(3.1 \mathrm{~nm})<\mathrm{PPC} /$ $\mathrm{CP} / \mathrm{ITO}(3.5 \mathrm{~nm})$. We believe that in the case of $\mathrm{Fc} / \mathrm{CP} / \mathrm{ITO}$, the lower thickness of the $\mathrm{CP}$ layer leads to the shorter distance between the FC and the ITO electrode, resulting in a higher $k_{\text {et }}$ compared to the other two surfaces.

\section{CONCLUSIONS}

In this study, PPC and CP aryldiazonium salts with different reductive potentials were deposited simultaneously or consecutively on ITO to form mixed layer surfaces. Using a simultaneous electrografting strategy, more reactive CP cations always showed priority on the surface compared to PPC cations. A consecutive electrografting strategy was then applied by depositing PPC diazonium cations first with higher concentration and favorable potential followed by depositing CP diazonium cations. A 200:1 surface composition of PPC/ CP was achieved using a consecutive electrografting strategy. The resultant mixed layer ITO surface maintains its antifouling properties and has accessible carboxylic acid moieties available for ferrocene decoration. In the future, such versatile mixed layer/ITO platforms will be employed by decorating biological species like redox proteins, antibodies, or DNA to develop real biodevices as has just been demonstrated for the detection of DNA sequences. ${ }^{45}$

\section{ASSOCIATED CONTENT}

\section{S Supporting Information}

The Supporting Information is available free of charge on the ACS Publications website at DOI: 10.1021/acs.langmuir.5b04550.

P 2p, N 1s, and C 1s core level XPS spectra for CP/ITO and PPC/ITO surfaces; N 1s core level spectra of PPC$\mathrm{CP}$ mixed layer/ITO surfaces modified by simultaneous electrografting; cyclic voltammograms recorded on PPC/ $\mathrm{CP} / \mathrm{ITO}$ surface before and after HSA incubation; cyclic voltammograms measured in $1.0 \mathrm{M} \mathrm{NaClO}_{4}$ at ITO surfaces modified with aryldiazonium cations and postfunctionalized with ferrocene; procedures for functionalize mixed layer/ITO surface with ferrocene; equation for calculation of total surface coverage $(\Gamma)$ of electroactive ferrocene (PDF)

\section{AUTHOR INFORMATION}

\section{Corresponding Author}

*Tel +61 (02) 9385 5384; e-mail justin.gooding@unsw.edu.au (J.J.G.).

\section{Present Address}

N.D.: Departament de Química Física, Universitat de Barcelona, Diagonal 645, Barcelona 08028, Spain.

\section{Notes}

The authors declare no competing financial interest.

\section{ACKNOWLEDGMENTS}

We thank the Australian Research Council Centre of Excellence in Convergent Bio-Nano Science and Technology (project number CE140100036) and the University of New South 
Wales for funding. Cheng Jiang appreciates China Scholarship Council (CSC) for scholarship.

\section{REFERENCES}

(1) Whitesides, G. M.; Laibinis, P. E. Wet chemical approaches to the characterization of organic surfaces: self-assembled monolayers, wetting, and the physical-organic chemistry of the solid-liquid interface. Langmuir 1990, 6 (1), 87-96.

(2) Le Saux, G.; Magenau, A.; Böcking, T.; Gaus, K.; Gooding, J. J. The relative importance of topography and RGD ligand density for endothelial cell adhesion. PLoS One 2011, 6 (7), e21869-e21869.

(3) Roberts, C.; Chen, C. S.; Mrksich, M.; Martichonok, V.; Ingber, D. E.; Whitesides, G. M. Using mixed self-assembled monolayers presenting RGD and (EG) $3 \mathrm{OH}$ groups to characterize long-term attachment of bovine capillary endothelial cells to surfaces. J. Am. Chem. Soc. 1998, 120 (26), 6548-6555.

(4) Vilà, N.; Bélanger, D. Mixtures of functionalized aromatic groups generated from diazonium chemistry as templates towards bimetallic species supported on carbon electrode surfaces. Electrochim. Acta 2012, 85, 538-547.

(5) Harper, J. C.; Polsky, R.; Wheeler, D. R.; Lopez, D. M.; Arango, D. C.; Brozik, S. M. A multifunctional thin film au electrode surface formed by consecutive electrochemical reduction of aryl diazonium salts. Langmuir 2009, 25 (5), 3282-3288.

(6) Khor, S. M.; Liu, G.; Fairman, C.; Iyengar, S. G.; Gooding, J. J. The importance of interfacial design for the sensitivity of a label-free electrochemical immuno-biosensor for small organic molecules. Biosens. Bioelectron. 2011, 26 (5), 2038-2044.

(7) Imahori, H.; Mori, Y.; Matano, Y. Nanostructured artificial photosynthesis. J. Photochem. Photobiol., C 2003, 4 (1), 51-83.

(8) Banet, P.; Marcotte, N.; Lerner, D. A.; Brunel, D. Single-step dispersion of functionalities on a silica surface. Langmuir 2008, 24 (16), 9030-9037.

(9) Collman, J. P.; Devaraj, N. K.; Eberspacher, T. P.; Chidsey, C. E. Mixed azide-terminated monolayers: a platform for modifying electrode surfaces. Langmuir 2006, 22 (6), 2457-2464.

(10) Lee, L. Y. S.; Sutherland, T. C.; Rucareanu, S.; Lennox, R. B. Ferrocenylalkylthiolates as a probe of heterogeneity in binary selfassembled monolayers on gold. Langmuir 2006, 22 (9), 4438-4444.

(11) Bain, C. D.; Whitesides, G. M. Formation of two-component surfaces by the spontaneous assembly of monolayers on gold from solutions containing mixtures of organic thiols. J. Am. Chem. Soc. 1988, 110 (19), 6560-6561.

(12) Chapman, R. G.; Ostuni, E.; Yan, L.; Whitesides, G. M. Preparation of mixed self-assembled monolayers (SAMs) that resist adsorption of proteins using the reaction of amines with a SAM that presents interchain carboxylic anhydride groups. Langmuir 2000, 16 (17), 6927-6936.

(13) Horn, A. B.; et al. Ageing of alkanethiol self-assembled monolayers. J. Chem. Soc., Faraday Trans. 1996, 92 (23), 4759-4762.

(14) Delamarche, E. a. A.; Michel, B.; Kang, H.; Gerber, C. Thermal stability of self-assembled monolayers. Langmuir 1994, 10 (11), 41034108.

(15) Garrell, R. L.; Chadwick, J. E.; Severance, D. L.; McDonald, N. A.; Myles, D. C. Adsorption of sulfur containing molecules on gold: the effect of oxidation on monolayer formation and stability characterized by experiments and theory. J. Am. Chem. Soc. 1995, 117 (46), 11563-11571.

(16) Leroux, Y. R.; Hapiot, P. Nanostructured monolayers on carbon substrates prepared by electrografting of protected aryldiazonium salts. Chem. Mater. 2013, 25 (3), 489-495.

(17) Mahouche-Chergui, S.; Gam-Derouich, S.; Mangeney, C.; Chehimi, M. M. Aryl diazonium salts: a new class of coupling agents for bonding polymers, biomacromolecules and nanoparticles to surfaces. Chem. Soc. Rev. 2011, 40 (7), 4143-4166.

(18) Polsky, R.; Harper, J. C.; Dirk, S. M.; Arango, D. C.; Wheeler, D. R.; Brozik, S. M. Diazonium-functionalized horseradish peroxidase immobilized via addressable electrodeposition: direct electron transfer and electrochemical detection. Langmuir 2007, 23 (2), 364-366.
(19) Santos, L.; Mattiuzzi, A.; Jabin, I.; Vandencasteele, N.; Reniers, F.; Reinaud, O.; Hapiot, P.; Lhenry, S.; Leroux, Y.; Lagrost, C. OnePot Electrografting of Mixed Monolayers with Controlled Composition. J. Phys. Chem. C 2014, 118 (29), 15919-15928.

(20) Mattiuzzi, A.; Jabin, I.; Mangeney, C.; Roux, C.; Reinaud, O.; Santos, L.; Bergamini, J.-F.; Hapiot, P.; Lagrost, C. Electrografting of calix [4] arenediazonium salts to form versatile robust platforms for spatially controlled surface functionalization. Nat. Commun. 2012, 3, 1130.

(21) Leroux, Y. R.; Hui, F.; Noël, J.-M.; Roux, C.; Downard, A. J.; Hapiot, P. Design of robust binary film onto carbon surface using diazonium electrochemistry. Langmuir 2011, 27 (17), 11222-11228.

(22) Gui, A. L.; Yau, H. M.; Thomas, D. S.; Chockalingam, M.; Harper, J. B.; Gooding, J. J. Using supramolecular binding motifs to provide precise control over the ratio and distribution of species in multiple component films grafted on surfaces: demonstration using electrochemical assembly from aryl diazonium salts. Langmuir 2013, 29 (15), 4772-4781.

(23) Liu, G.; Chockalingham, M.; Khor, S. M.; Gui, A. L.; Gooding, J. J. A comparative study of the modification of gold and glassy carbon surfaces with mixed layers of in situ generated aryl diazonium compounds. Electroanalysis 2010, 22 (9), 918-926.

(24) Louault, C.; D’Amours, M.; Belanger, D. The electrochemical grafting of a mixture of substituted phenyl groups at a glassy carbon electrode surface. ChemPhysChem 2008, 9 (8), 1164-70.

(25) Gam-Derouich, S.; Gosecka, M.; Lepinay, S.; Turmine, M.; Carbonnier, B.; Basinska, T.; Slomkowski, S.; Millot, M.-C.; Othmane, A.; Ben Hassen-Chehimi, D. Highly hydrophilic surfaces from polyglycidol grafts with dual antifouling and specific protein recognition properties. Langmuir 2011, 27 (15), 9285-9294.

(26) Liu, G.; Gooding, J. J. An interface comprising molecular wires and poly (ethylene glycol) spacer units self-assembled on carbon electrodes for studies of protein electrochemistry. Langmuir 2006, 22 (17), 7421-7430.

(27) Liu, G.; Wang, S.; Liu, J.; Song, D. An electrochemical immunosensor based on chemical assembly of vertically aligned carbon nanotubes on carbon substrates for direct detection of the pesticide endosulfan in environmental water. Anal. Chem. 2012, 84 (9), 3921-3928.

(28) Santos, L.; Ghilane, J.; Lacroix, J. C. Formation of mixed organic layers by stepwise electrochemical reduction of diazonium compounds. J. Am. Chem. Soc. 2012, 134 (12), 5476-5479.

(29) Lee, L.; Brooksby, P. A.; Leroux, Y. R.; Hapiot, P.; Downard, A. J. Mixed monolayer organic films via sequential electrografting from aryldiazonium ion and arylhydrazine solutions. Langmuir 2013, 29 (9), $3133-3139$

(30) Liu, G.; Paddon-Row, M.; Gooding, J. Protein modulation of electrochemical signals: application to immunobiosensing. Chem. Commun. (Cambridge, U. K.) 2008, 33, 3870-3872.

(31) Gui, A. L.; Luais, E.; Peterson, J. R.; Gooding, J. J. Zwitterionic phenyl layers: finally, stable, anti-biofouling coatings that do not passivate electrodes. ACS Appl. Mater. Interfaces 2013, 5 (11), 482735.

(32) Parviz, M.; Darwish, N.; Alam, M. T.; Parker, S. G.; Ciampi, S.; Gooding, J. J. Investigation of the Antifouling Properties of Phenyl Phosphorylcholine-Based Modified Gold Surfaces. Electroanalysis 2014, 26 (7), 1471-1480.

(33) Jiang, C.; Tanzirul Alam, M.; Parker, S. G.; Gooding, J. J. Zwitterionic Phenyl Phosphorylcholine on Indium Tin Oxide: a LowImpedance Protein-Resistant Platform for Biosensing. Electroanalysis 2015, 27 (4), 884-889.

(34) Ciampi, S.; James, M.; Michaels, P.; Gooding, J. J. Tandem "click" reactions at acetylene-terminated Si (100) monolayers. Langmuir 2011, 27 (11), 6940-6949.

(35) Seah, M.; Dench, W. Quantitative electron spectroscopy of surfaces: a standard data base for electron inelastic mean free paths in solids. Surf. Interface Anal. 1979, 1 (1), 2-11. 
(36) Wildgoose, G. G.; Banks, C. E.; Compton, R. G. Metal nanoparticles and related materials supported on carbon nanotubes: methods and applications. Small 2006, 2 (2), 182-193.

(37) Banks, C. E.; Davies, T. J.; Wildgoose, G. G.; Compton, R. G. Electrocatalysis at graphite and carbon nanotube modified electrodes: edge-plane sites and tube ends are the reactive sites. Chem. Commun. 2005, 7, 829-841.

(38) Daniel Bélanger, J. P. Electrografting: a powerful method for surface modification. Chem. Soc. Rev. 2011, 40, 3995-4048.

(39) Combellas, C.; Kanoufi, F.; Pinson, J.; Podvorica, F. I. Sterically hindered diazonium salts for the grafting of a monolayer on metals. $J$. Am. Chem. Soc. 2008, 130 (27), 8576-8577.

(40) Chen, S.; Zheng, J.; Li, L.; Jiang, S. Strong resistance of phosphorylcholine self-assembled monolayers to protein adsorption: insights into nonfouling properties of zwitterionic materials. J. Am. Chem. Soc. 2005, 127 (41), 14473-14478.

(41) Chen, S.; Liu, L.; Jiang, S. Strong resistance of oligo (phosphorylcholine) self-assembled monolayers to protein adsorption. Langmuir 2006, 22 (6), 2418-2421.

(42) Creager, S. E.; Wooster, T. T. A new way of using ac voltammetry to study redox kinetics in electroactive monolayers. Anal. Chem. 1998, 70 (20), 4257-4263.

(43) Smalley, J. F.; Feldberg, S. W.; Chidsey, C. E.; Linford, M. R.; Newton, M. D.; Liu, Y.-P. The kinetics of electron transfer through ferrocene-terminated alkanethiol monolayers on gold. J. Phys. Chem. 1995, 99 (35), 13141-13149.

(44) Guo, L.-H.; Facci, J. S.; McLendon, G. Distance dependence of electron transfer rates in bilayers of a ferrocene Langmuir-Blodgett monolayer and a self-assembled monolayer on gold. J. Phys. Chem. 1995, 99 (21), 8458-8461.

(45) Kuo, T.-M.; Shen, M.-Y.; Huang, S.-Y.; Li, Y.-K.; Chuang, M.-C. Facile Fabrication of a Sensor with a Bifunctional Interface for Logic Analysis of the New Delhi Metallo- $\beta$-Lactamase (NDM)-Coding Gene. ACS Sensors 2016, 1, 124-130. 